\title{
Aspectos Emocionais Vivenciados pelos Pais e/ou Cuidadores de Crianças com Alergia à Proteína do Leite de Vaca
}

\author{
Raíza Maria de Aquino Abagaro ${ }^{1}$; Thércia Lucena Grangeiro Maranhão ${ }^{2}$; \\ Nicole Ggonçalves Nascimento Rocha ${ }^{3}$; Stevens Emanuel Cecílio Sobral ${ }^{4}$; Maria Lindinez Cecílio Sobral ${ }^{5}$
}

\begin{abstract}
Resumo: A alimentação é uma necessidade básica do ser humano, porém muitos alimentos podem desencadear reações adversas em qualquer etapa da vida. As alergias, como podem ser chamadas uma dessas reações, decorrem desde o nascimento até a vida adulta, trazendo angústias e preocupações não somente para a criança, como também para aqueles que a rodeiam, seus cuidadores. Esta pesquisa teve como objetivo principal identificar os impactos vivenciados pelos cuidadores de crianças com alergia à proteína do leite de vaca (APLV). Para tanto, buscou, além de explicar como se caracteriza a alergia à proteína do leite de vaca em crianças, seus sintomas e tratamento, compreender, através de pesquisa bibliográfica, quais as dificuldades encontradas no cuidados com crianças com APLV. Utilizou-se, como método de estudo, a pesquisa bibliográfica qualitativa, através de busca livre nas bases de dados nacionais. Percebeu-se que os impactos enfrentados pelos cuidadores das crianças com APLV estão ligados principalmente ao processo de diagnóstico, pois os sintomas são diversos; à adaptação pessoal, familiar e social; à dieta restritiva; aos cuidados com a contaminação cruzada, através de utensílios domésticos; à introdução de fórmulas artificiais de alto custo e à aprendizagem da leitura dos rótulos dos produtos industrializados. Os resultados apontaram a necessidade de dedicar uma atenção não somente à criança com APLV, mas também aos seus cuidadores que, de acordo com os dados obtidos, enfrentam desafios e incertezas que merecem cuidado multiprofissional.
\end{abstract}

Palavras-chave: Alergia à proteína de vaca. Alimentação. Impactos. Cuidadores.

\section{Emotional Aspects Experienced by Parents and / or Caregivers of Children With Allergy to Cow's Milk Protein}

\begin{abstract}
The food is a basic human need it, however, any food can trigger adverse reactions at any stage of life. The allergies, they may be called it one of these reactions, run from birth to adulthood, bringing distress and worry not only to the child, but also to those around them, their caregivers. This research had as main objective to identify the impacts experienced by caregivers of children with cow's milk protein allergy (APLV). In order to do so, he sought, besides explaining how the allergy to cow's milk protein in children, their symptoms and treatment is characterized, understood, through a semi-structured interview, the difficulties encountered in the care of children with APLV and analyzed in speeches the impacts on the care of children with the aforementioned allergy. Qualitative bibliographic research was used as a method of study through free search in the national databases. It was noticed that the impacts faced by the caregivers of the children with APLV are mainly related to: the diagnostic process, because the symptoms are diverse; to personal, family and social adjustment; restrictive diet; care with cross-contamination through household utensils; the introduction of expensive artificial formulas; and learning to read the labels of industrialized products. The results pointed out the need to devote attention not only to the child with APLV, but also to their caregivers who, according to the data obtained, face challenges and uncertainties that deserve multiprofessional care.
\end{abstract}

Key words: Allergy to cow protein. Feeding. Emotional Aspects. Caregivers.

${ }^{1}$ Graduada do curso de Psicologia pelo Centro Universitário Doutor Leão Sampaio; E-mail: aquino.raiza@ gmail.com.

${ }^{2}$ Psicóloga , Graduada pela Faculdade de Ciências Humanas de Recife - ESUDA ,Especialista em Gestão do Trabalho e da Educação na Saúde pela Escola de Saúde Pública do Estado do Ceará .Pós- Graduanda da Faculdade de Medicina do ABC, do curso de Mestrado em Ciências da Saúde. Professora do Centro Universitário Dr. Leão Sampaio ;Membro do Comitê de Ética em Pesquisa da UNILEÃO. Coordenadora do Núcleo Cariri da ABRH-CE. E-mail: thercia@leaosampaio.edu.br;

${ }^{3}$ Graduação em Medicina pela Faculdade de Medicina Estacio de Juazeiro do Norte. Nicolegn.medicina@live.com;

${ }^{4}$ Farmacêutico pela Uninassau. Contato: stevens_emanuel@ hotmail.com;

${ }^{5}$ Medicina pela Faculdade de Medicina Estácio de Juazeiro do Norte-CE. ninacecilio@ hotmail.com:

736 Id on Line Rev. Mult. Psic. V.12, N. 39. 2018 - ISSN 1981-1179

Edição eletrônica em http://idonline.emnuvens.com.br/id 


\section{Introdução}

A alimentação, além de ter função fisiológica, é uma uma necessidade básica de todos os seres humanos. Diversos alimentos podem desencadear reações adversas, em qualquer etapa da vida, trazendo angústias e preocupações, podendo ocorrer desde o nascimento até a vida adulta. A chamada alergia ocorre quando uma substância, inofensiva até então, provoca reação imune com sintomas em alguns indivíduos. A alergia alimentar é uma resposta a alimentos específicos, envolvendo mecanismos imunológicos (BRICKS et al., 2008).

Esta pesquisa estuda sobre uma dessas reações alérgicas, mais especificamente a Alergia à Proteína do Leite de Vaca (APLV). De acordo com Bricks et al. (2008), 29,3\% dos tipos alergias registrados em sua pesquisa, eram APLV. Essa, atinge principalmente crianças com baixa idade, menores de 3 anos, com diagnóstico expedido geralmente a partir dos 6 meses de idade, que é quando comumente acontece a introdução alimentar da criança, até os 18 meses. Crianças menores de 3 anos, alérgicas à PLV, podem reduzir os sintomas com a dieta de exclusão, segundo a Solé (2007).

Para os cuidadores destas crianças, a introdução alimentar, período cheio de grandes descobertas e prazer, acaba tornando-se um momento de frustração e intenso estresse, pois envolve uma série de cuidados e um processo adaptativo, muitas vezes envolvendo todo o ambiente familiar (DIAS, 2016). Assim posto, esta pesquisa busca conhecer esses desafios enfrentados pelos cuidadores de crianças com APLV.

Esta pesquisa também apresentará alguns fatores que podem ser predisponentes para a alergia à proteína do leite de vaca e como essas condições contribuem para o processo de adaptação dos cuidadores das crianças com APLV, pois sabe-se que a alergia alimentar é mais frequente em crianças. A saber, a prevalência seja em torno de $6 \%$ em crianças de três anos e de 3,5\% em adultos e segundo esta pesquisa, esse número tem aumentado a cada ano (SOLÉ et al., 2007).

Após intensa leitura sobre a temática e seus aspectos biológicos, epidemiológicos e psicológicos, tendo por base anterior publicadas e indexadas em bases de dados como: BVS e SCIELO, iniciou-se uma compilação de produções científicas que abordassem a APLV e suas principais contribuições para a proposta da pesquisa supracitada.

A alimentação de uma criança é permeada de grandes descobertas e desafios para as(os) cuidadoras(es), dentre eles, destaca-se aqui nesta pesquisa, a Alergia à proteína do 
Leite de Vaca (APLV). Segundo Dias (2016), a APLV é dominante e mais frequente entre as crianças de até um ano de idade. Combinado a todos os cuidados necessários a um bebê, o tratamento realizado é permeado de grandes desafios.

Pensando nesta temática, a autora propõe o referido estudo, buscando nas suas justificativas pessoal, acadêmica e social, a reflexão acerca dos aspectos emocionais envolvidos no cotidiano de cuidados da criança com APLV. Tendo em vista a importância dos fatores emocionais na promoção e manutenção do aleitamento materno na tentativa de evitar o desmame precoce, mesmo diante de fatores que podem tornar-se barreiras, como a APLV, começamos a delinear o presente estudo na tentativa de identificar os aspectos emocionais vivenciados pelos pais de crianças com APLV.

A escolha pessoal pelo tema baseia-se nas experiências vividas na primeira e segunda gestação da autora. Mãe de dois filhos com alergia à proteína do leite de vaca, enfrentou desafios na busca pela cura dos filhos. No decorrer do processo, obteve suporte médico quanto ao tratamento dos bebês, ainda que a APLV seja um tema púbere na medicina. O que salienta a autora como sendo um grande prejuízo para a mesma, foi a ausência de suporte emocional enquanto nutriz, mergulhada em uma dieta de exclusão de leite e derivados, renunciando a alimentos considerados essenciais na cadeia alimentar, mudando toda a rotina de uma família. Percebeu-se que o tratamento baseia-se apenas em fatores biológicos, deixando para trás os fatores emocionais que permeiam as famílias de crianças com APLV.

Percebeu-se também, no que tange a produção científica, a atenção dispensada na academia ao tema proposto, já que há uma ausência de estudos que versem sobre os aspectos emocionais, principalmente como uma área de estudo dentro da psicologia do desenvolvimento infantil e psicologia da família. Há escassez, também, de pesquisas que envolvem as implicações nas relações familiares de alérgicos quanto a necessidade de adaptar-se às mudanças para evitar reações e promover uma melhor qualidade de vida (GOMES et al., 2017).

Este artigo consiste em uma pesquisa bibliográfica qualitativa de cunho exploratório, que, segundo Gil (2008), corresponde a um método de estudo que tem como principal meta proporcionar maior familiaridade e conhecimento de um determinando problema, a fim de torná-lo mais explícito, a partir das explicações e interpretações sobre o tema em estudo.

As etapas realizadas nesta pesquisa seguiram a proposta de Minayo (1993): (1) o Levantamento de produções científicas sobre APLV em crianças e os impactos em seus 
cuidadores (2) Seleção do material encontrado através de uma leitura flutuante dos artigos; (3) fichamento dos artigos selecionados em etapa anterior; e (4) Análise e Interpretação das informações, proporcionando um diálogo entre as teorias básica do referencial teórico utilizado e os dados encontrados e selecionados anteriormente.

Os dados deste estudo foram coletados e analisados no período de julho e novembro de 2017 em bases de dados online. Utilizando como descritores: "APLV", "cuidadores" e "impactos". A busca ocorreu no âmbito científico nacional. Após esta etapa, encontrou-se muitos artigos sobre a temática, necessitando, portanto, de alguns critérios de inclusão, a saber texto completo disponível, idioma português e por assunto principal (a saber, impacto nos cuidadores/pais/mães/família). Após esta seleção, apenas 6 (seis) artigos foram selecionados para a segunda etapa.

Foram realizadas leituras e fichamentos dos artigos selecionados, analisados de modo qualitativo e utilizados segundo a relevância para a realização deste trabalho. Além dessa base de dados, utilizou-se ainda, artigos selecionados de acordo com a relevância, pertinência e que auxiliassem na compreensão e assimilaçao do conteúdo do presente estudo.

\section{Alergia à Proteína do Leite de Vaca (APLV): Caracterização e Cuidado}

\section{Alergia Alimentar (AA)}

A alimentação, além de ter função fisiológica, é uma necessidade básica de todos os seres humanos. Diversos alimentos podem desencadear reações adversas, em qualquer etapa da vida, trazendo angústias e preocupações. Podem ocorrer desde o nascimento até a vida adulta, caracterizando-se, portanto como doença crônica. Quando acontece na infância pode abarcar todas as enfermidades de base biológica, psicológica ou cognitiva, exigindo cuidados específicos por um longo período de tempo, igual ou superior a três meses, com o uso de medicação, dietas especiais, limitação funcional e cuidados médicos específicos (LINHARES, 2015).

A chamada alergia é uma resposta a alimentos específicos, envolvendo mecanismos imunológicos, e ocorre quando uma substância, inofensiva até então, provoca reação imune com sintomas em alguns indivíduos. Na infância, pode gerar impacto no rendimento funcional 
da criança, já que algumas crianças vivenciam constantes internações e passam por agravamento de suas condições físicas. (AZEVEDO et al., 2013).

$\mathrm{Na}$ alergia alimentar (AA) os sistemas do corpo humano diretamente envolvidos são o imunológico e digestório, porém as influências não se limitam aos aspectos físicos da criança. Podem ocorrer ainda influência no desenvolvimento emocional; restrição da autonomia da criança; apatia e passividade (CASTRO, PICCININI, 2002). Esses problemas afetam não só a criança, mas também a sua família e principalmente o seu cuidador primário. Entende-se por cuidador primário, a pessoa que assume a maior parte das tarefas relacionadas aos cuidados com a criança, dividindo o tempo de suas responsabilidades habituais com a agenda de cuidados específicos da criança com AA (LINHARES, 2015).

As alergias podem ser classificadas de acordo com os mecanismos imunológicos envolvidos: IgE Mediada: as reações são imediatas. Surgem de segundos até duas horas após o consumo do leite de vaca ou derivados. São chamadas desta forma, porque o próprio organismo produz anticorpos do tipo $\operatorname{IgE}$ (Imunoglubulinas $\mathrm{E}$ ) para a(s) proteína(s) do leite de vaca da qual a criança é alérgica. Os sintomas são diversos, entre eles podemos citar: urticária (manchas vermelhas que podem aparecer em partes específicas ou espalhadas por todo corpo e geralmente causam coceira), vômitos, diarréia, choque anafilático, respiração difícil e chiado no peito (SOUZA, 2016).

IgE não mediada: comumente as reações aparecem tardiamente, surgindo algumas horas ou até dias após o consumo do leite. Pode ser definida como uma reação mediada por células, o organismo não produz anticorpos $\operatorname{IgE}$ específicos. Nesses casos a reação é desencadeada por outras células. Crianças não mediadas normalmente alcançam a cura antes que as demais. Os sintomas também são diversificados, a depender de cada organismo. Entre as reações mais comuns, podemos citar: vômitos tardios, baixo ganho de peso e crescimento, podendo levar a desnutrição, inflamação no intestino, refluxo, assadura perianal, diarréia com a presença de muco, sangue nas fezes, irritabilidade e cólicas (SOUZA, 2016; MEDEIROS, 2013).

Ainda existem as crianças que apresentam alergia mista. As reações nesse caso podem ser imediatas ou tardias, após consumir o leite de vaca ou seus derivados. A alergia pode ser definida em algumas crianças apresentando os dois tipos. Entre os sintomas é possível citar: refluxo, inflamação no estômago, baixo ganho de peso e, consequentemente, crescimento 
comprometido, asma, diarréia, dor abdominal, dermatite atópica (ressecamento da pele em locais específicos ou espalhadas pelo corpo) (PINTO, 2013).

Quando qualquer membro do círculo familiar necessita de cuidados especiais, inclusive com a alergia alimentar, a organização e a estrutura familiar são remontadas, remodeladas, afetando de forma particular e direta os seus cuidadores primários, dos quais 90\% são os próprios familiares. Estes, buscam qualificação e informação sobre o tratamento e a coordenação dos cuidados prestados, gerando mudanças drásticas na rotina (LINHARES, 2015).

Tais mudanças podem trazer estresse e sobrecarga ao cuidador, ocasionando mudanças no tratamento e na evolução da AA da criança, acrescenta-se, ainda, que essas respostam são diretamente influenciadas pelas crenças, pelos valores e pelas experiências do cuidador e dos seus pares. Os principais alimentos considerados alergênicos são: leite de vaca, soja, ovo, trigo, peixe, frutos do mar, amendoim e castanhas. Esses oito alimentos podem desencadear reações alérgicas, somando $90 \%$ dos casos de alergia. Os outros $10 \%$ são a outros alimentos não listados. O leite de vaca se apresenta como o maior causador de AA na infância, provavelmente por ser o alimento do grupo supracitado mais ofertado, muitas vezes como alimento único na dieta dessa população e com o maior potencial alergênico (LINHARES, 2015).

\section{Alergia à Proteína do Leite de Vaca: Definição, Diagnóstico e Evolução}

A Alergia à Proteína do Leite de Vaca ou APLV, pode ser definida como uma reação adversa do sistema imunológico às proteínas presentes no leite de vaca, principalmente a Caseína, a Alfa-Lactoalbumina e a Beta-Lactoglobulina (LINHARES, 2015).

É preciso ainda frisar que existe uma vasta diferença entre alergia a proteína do leite de vaca e intolerância a lactose. Essa afirmação costuma causar confusão entre as famílias, os cuidadores e até a equipe de saúde. A intolerância à lactose pode ser explicada pela carência ou deficiência da enzima lactase, que é responsável pela quebra da lactose- o açúcar encontrado no leite de vaca e seus derivados. Com a ausência ou o com a diminuição do funcionamento da lactase, o açúcar não é digerido, e quando o mesmo chega ao intestino, provoca reações como distensão abdominal, gases e cólicas. A intolerância à lactose se 
apresenta mais comumente na vida adulta, mas pode-se apresentar em bebês e crianças também, e não caracteriza-se como uma alergia alimentar, uma vez que as alergias são causadas pelas proteínas e nos açúcares não é possível encontrar proteínas (RODRIGUES; RODRIGUES, 2011; SOUZA, 2016; TEIXEIRA, 2010).

Apesar do grande número de crianças acometidas com esse tipo de alergia, entre 6 e $8 \%$ das crianças, não têm o diagnóstico fechado precocemente. $\mathrm{O}$ diagnóstico é baseado prioritariamente na história clínica do paciente, demandando dos familiares uma capacidade recordatória dos sintomas, além da sensibilidade médica de elaborar um bom diagnóstico diferencial (LINHARES, 2015).

Segundo Souza (2016), além da análise clínica do paciente, também é possível chegar ao diagnóstico de crianças mediadas através de exames de sangue ou testes cutâneos. Em crianças não mediadas ou mistas, os exames não apresentam eficácia quanto aos resultados, que quase sempre, apontam um resultado falso negativo. Também é muito utilizado o exame de coprologia funcional com pesquisa de sangue oculto. Este é um exame feito em laboratório que identifica pequenas quantidades de sangue presentes nas fezes, invisíveis a olho nu. O sangue presente nas fezes se apresenta como uma reação inflamatória do intestino causada pela alergia à proteína do leite de vaca.

Percebe-se que a ausência de um atendimento clínico mais detalhado ao deparar-se com os sintomas, pode acarretar em diagnóstico tardio e, consequentemente, em um prolongamento do sofrimento da criança e do seu cuidador. Mesmo assim, sabe-se que o diagnóstico da APLV deve ser realizado com muita cautela, sendo executados testes de provocação e exclusão do alimento, associado a testes cutâneos de hipersensibilidade, etc. como supracitado (GUERRA; BARRETO, 2016; SOUZA, 2016).

Observa-se que a sintomatologia variada dificulta o diagnóstico da APLV, colocando em risco a integridade física da criança. E os erros diagnósticos levam os pais a desacreditarem da equipe médica, que ou subestimam os sintomas apresentados, ou, em outros casos os hiperestimam, levando os pacientes a dietas restritivas com repercussões nutricionais importantes e desnecessárias ou até mesmo a exposição desnecessária à drogas farmacológicas (SOLÉ et al., 2007).

Quanto à evolução da APLV, o paciente pode demonstrar uma melhora no quadro clínico quando apresenta alguma característica do mecanismo imunológico responsável pelas manifestações clínicas; quando está recebendo uma terapêutica eficaz; e quando são avaliadas 
as características do paciente. Algumas crianças alérgicas desenvolvem tolerância ao leite de vaca ainda na infância, já outros, entretanto, podem permanecer com algum grau de sensibilidade por anos, necessitando de cuidados especiais (LINHARES, 2015).

\section{Tratamento da APLV}

Por se tratar de uma AA, a APLV é controlada essencialmente através de controle nutricional, baseando-se em dois pilares: a) a exclusão do alérgeno alimentar responsável pelo quadro clínico; e b) o uso de fórmulas ou dietas hipoalergências. Para as crianças que não estão em aleitamento materno exclusivo, a conduta é prescrever fórmulas infantis hidrolisadas ou extensamente hidrolisadas. Para crianças em aleitamento materno exclusivo, recomenda-se a exclusão de leite e derivados da dieta da mãe. (LINHARES, 2015).

$\mathrm{O}$ aleitamento materno exclusivo durante os seis primeiros meses de vida parece ter um efeito protetor na diminuição da incidência de APLV. Estudos mostram que, quando a amamentação exclusiva é inferior a esse período, principalmente quando a interrupção ocorre antes dos 4 meses, as chances de desenvolver doenças crônicas como a alergia, são maiores. A principal vantagem da amamentação na redução da sensibilização e dos sintomas de APLV, em bebês já sensibilizados, é a relativa escassez de antígenos no leite materno. A melhor dieta para os recém-nascidos e os lactentes é o leite materno, já que, além de apresentar todos os nutrientes ideais para o bebê, tem função importante no desenvolvimento das funções imunológicas e da microbiota intestinal. O leite materno, conforme a necessidade da criança, vai adaptando-se e modificando-se (CEZA; FERREIRA, 2015).

Entretanto, pequenas quantidades da proteína do leite de vaca ingeridas pela mãe podem ser transferidas através do leite materno, na amamentação. Por isso, algumas mães precisam passar por uma dieta de restrição, para evitar totalmente o risco de reações da APLV (TEIXEIRA, 2010). Mesmo assim, é parte fundamental do tratamento e adaptação familiar à APLV.

Gomes e outros (2017) traz que o início do processo de diagnóstico é permeado de ansiedade e de dúvidas por parte dos pais, que a partir daí, buscam conhecer e se informar sobre a APLV. Logo em seguida, já elaboram estratégias de ação para lidar com a doença, o 
nível de ansiedade diminui, mas a vigilância permace alta. Alguns pais ainda mantém o nível de ansiedade constante, o que contribui para uma vigilância maior, principalmente quando há risco de contaminação iminente.

Outro ponto bastante relevante do tratamento da criança com APLV é a educação e a informação sobre o alimento. A leitura dos rótulos, o conhecimeno dos ingredientes ao comer fora de casa e o evitar o contato com alimentos que, em qualquer etapa do processo de preparo, entraram em contato com leite e seus derivados, ou até alimentos com traços de leite (inclusive instrumentos utilizados na cozinha, como faca, tábuas de corte, etc) (DIAS, 2016; GOMES et al., 2017). Como considera Cardoso (2012), quando afirma que os cuidados não giram somente em torno da alimentação, mas de todo o ambiente no qual a criança terá contato durante o tratamento da APLV. Os aspectos envolvidos na orientação do paciente e, no caso de crianças, orientação aos cuidadores, englobam a leitura dos rótulos, a contaminação cruzada, os cuidados fora de casa, a escolha do melhor substituto do LV e o fornecimento de orientações práticas.

Percebe-se que a informação, a educação nutricional e o reforço da importância da exclusão completa do leite de vaca e dos seus derivados da dieta da criança e até, em alguns casos da família, com a participação de equipe multiprofissional, são essenciais para o sucesso do tratamento. Além desses cuidados de separar utensílios, para evitar riscos de contaminação cruzada, cuidados com ambientes de risco, como escolas e restaurantes, por exemplo. Há outro ponto que merece total atenção dos cuidadores: a leitura criteriosa e a interpretação adequada dos rótulos de alimentos e, outros produtos industrializados como cosméticos e medicamentos (YONAMINE, 2013).

A Agência Nacional de Vigilância Sanitária (ANVISA) normatizou a rotulação dos produtos industrializados, que entrou em vigor no dia 3 de julho de 2016, com o prazo de um ano para que as empresas se adequem às normas e informem nos seus rótulos se contém leite ou traços de leite por contaminação cruzada, facilitanto a identificação dos alérgenos nos produtos e garantindo a segurança alimentar para o consumo (GOMES et al., 2017).

A vigilância constante dos cuidadores é necessária até mesmo no momento de medicar a criança, pois muitos medicamentos e vacinas contém, nas suas formulações, leite ou traços de leite. Isso se aplica à cosmetica também. Muitas crises alérgicas acontecem e a sua causa permanece obliterada justamente pela falta dessas informações. Quanto à intervenção medicamentosa, Dias (2016) acrescenta que vários fármacos proporcionam alívio dos 
sintomas da APLV. A adrenalina, por exemplo, se necessário, poderá atenuar os sintomas mais graves rapidamente, como nos casos de choque anafilático. Os anti-histamínicos reduzem, parcialmente, os sintomas da síndrome de alergia oral e os sintomas cutâneos da alergia mediada por IgE.

Há ainda, um tratamento ideal que é realizado a base de hidrolisados proteicos, as chamadas fórmulas, que são proteínas muito fracionadas que formam aminoácidos de fácil absorção, conforme acrescenta Sekita (2015). As fórmulas tem alto custo e são fornecidas pelo governo para as famílias de baixa renda. Essa fórmula de aminoácidos, em consequência da hidrólise que é submetida, tem sabor impalatável, sendo mais facilmente aceita por crianças menores de seis meses (MEDEIROS, 2013).

Sendo assim, o tratamento mais comum é a abstenção dos alimentos alérgenos e, em caso de ingestão acidental, a terapêutica de emergência. Por esse motivo, as crianças demandam mais atenção em casa, na escola, em acampamentos, em restaurantes, em festas, etc. Este estado de hipervigilância, juntamente com o medo de uma ingestão acidental podem levar à redução da qualidade de vida relacionada com a saúde (DIAS, 2016).

Quanto à evolução da APLV, o paciente pode demonstrar uma melhora no quadro clínico quando apresenta alguma característica do mecanismo imunológico responsável pelas manifestações clínicas; quando está recebendo uma terapêutica eficaz; e quando são avaliadas as características do paciente. Algumas crianças alérgicas desenvolvem tolerância ao leite de vaca ainda na infância, já outros, entretanto, podem permanecer com algum grau de sensibilidade por anos, necessitando de cuidados especiais (LINHARES, 2015).

\section{Relação Mãe-Bebê com APLV}

A experiência da maternidade, acompanhada das suas angústias, desconfortos físicos e psicológicos, geralmente é enfrentada de maneira solitária. Segundo Veríssimo (2009), a ambivalência de sentimentos que a mãe passa ao dar a luz, é divergente do sentimento e planos que a acompanhavam na gestação. Esse momento é ilustrado por um novo relacionamento, dependente. Aduzindo vivências de emoções, angústias, prazer, raiva, medo, alegria, insegurança e muitas expectativas. Essa ambivalência evidencia-se quando a chegada do bebê real é acompanhada de alguma doença, no caso específico dessa pesquisa, a APLV. 
As expectativas criadas pela mãe antes do nascimento podem reverberar tanto de maneira positiva quanto de maneira negativa para o bebê e para a relação entre mãe-bebê. Os aspectos positivos envolvem, principalmente, a necessidade de que o bebê exista no imaginário da mãe, cheia de fantasias e desejos. Já as expectativas negativas ocorrem quando não há espaço para que o bebê seja quem é, verdadeiramente, com suas particularidades ou necessidades especiais. Se a relação entre mãe e bebê saudável é permeada por ambivalência e frustração, a relação mãe-bebê com APLV é permeada pelo luto do bebê ideal, perfeito e imaginário. Por conseguinte, torna-se necessário compreender que se essa relação supradita entre mãe-bebê real não sadio, as frustrações e ambivalências são mais intensas (PICCININI et al., 2004).

Algumas mães se deparam muito previamente com o bebê real não saudável e enfrentam uma experiência mais delicada, pois o problema pode envolver o aleitamento materno: é o caso de mães de bebês com alergia à proteína do leite de vaca. Apesar da indicação para amamentar em casos de crianças com APLV, podem surgir difculdades, por se tratar de uma tarefa complicada, que demanda tempo e dedicação para funcionar e para que seja estabelecida uma relação entre a mãe e o bebê. Nesse momento, o auxílio de outras pessoas torna-se fundamental (VERÍSSIMO, 2009).

A maternidade, enquanto um acontecimento humano contemporâneo, pode ser considerada um momento de frustração e sofrimento social quando observada nas relações concretas de vida. A sociedade ainda coloca a mulher como única e melhor cuidadora do filho, mesmo havendo significativos avanços (VISINTIN, 2016).

A mãe, além das funções que já acumula no seu dia a dia, ainda possui a função de sincronizar os ritmos de vida da criança. Esta função deve ser parte da relação estabelecida, onde a mãe percebe as peculiaridades do bebê e suas necessidades, assim o filho conhece a si mesmo, e permite que o mundo conheça e reconheça o resultado de suas ações. O desenvolvimento da criança depende do ritmo de vida estabelecido pelo par mãe-bebê, que influi na evolução da organização corporal, pessoal e individualizada. Quando a mãe é a cuidadora da criança, as suas vivências são cheias de afeto, que o deixa pensar, conectar-se com o mundo e perceber-se como um ser diferente e separado da mãe, dotado de necessidades individuais específicas (VERÍSSIMO, 2009). 


\section{Fatores Emocionais Presentes no Cuidado da Criança com APLV}

Como referido no tópico anterior, se a relação mãe-bebê já é entremeada por frustrações e sentimentos ambivalentes, quando esse bebê chega acompanhado de alguma doença, a frustração é ainda maior e a ambivalência se torna mais presente. De acordo com Dias (2016), pode-se inferir que esses sentimentos tornam-se mais intensos quando a mãe depara-se com o bebê real, diferente daquele idealizado, e carregando uma "imperfeição". Algumas mães enfrentam problemas ao se deparar, muito precocemente, com o bebê real não saudável,enfrentando uma situação delicada que requer sua dedicação e entrega, o aleitamento materno, como é o caso de mães de bebês com APLV.

Sentimento de culpa e sofrimento por parte da mãe do bebê com APLV são as principais queixas, pois como em alguns casos, o filho tem uma dieta alimentar restritiva, ela não pode alimentar-se normamente. E, além disso, ainda tem a função de manter o equilíbrio no ambiente familiar, atendendo às demandas dos demais membros da família (YONAMINE, 2013).

Há produções científicas que evidenciam os efeitos prejudiciais da alergia alimentar não somente nas crianças, mas também dos pais e/ou cuidadores. Dias (2016) defende que estas pesquisas servem como instrumento para a identificação e possível proteção, orientação e ajuda às crianças. Há diversos estudos e questionários que avaliam, quantitativa e qualitativamente, e comparam a saúde e as comorbidades entre pessoas doentes e saudáveis, porém que não conseguem abarcar aspectos psicológicos com a atenção necessária.

A qualidade de vida relacionada à saúde de crianças com AA e seus cuidadores, quando comparada com pessoas sem esse diagnóstico, diferem em subdomínios específicos, porém ainda é insuficiente a atenção dada pelos estudos atuais. É necessário um aumento das produções científicas e a elaboração de instrumentos que atendam a demanda específica da saúde mental dos pais ou cuidadores de crianças com APLV, além disso, é preciso relatar resultados significativamente relevantes para intervenção nesse público (GOMES et al., 2017).

As mães culpam-se pelos problemas de saúde dos filhos e, comumente, assumem total responsabilidade pelo cuidado, já que os filhos com APLV são bem jovens e exigem muita 
atenção e dedicação dos seus cuidadores, pois nessa faixa etária ainda necessitam de atenção especial e não têm maturidade suficiente para entender o seu problema, recaindo sobre os cuidadores a função da manutenção do bem-estar dessas crianças. Em caso de falha dessa função, há possibilidade do aumento do risco de contato com o alérgeno, e o consequente surgimento das reações adversas é eminente. Portanto, o medo da contaminação se torna uma sombra na vida dessas famílias, a dificuldade na leitura dos rótulos e de compreensão pelos outros membros da família, assim como pelos amigos faz com que as famílias acabem restringindo a sua vida social e de lazer (LINHARES, 2015).

Vários estudos, conforme Pinto (2013), trazem que as atividades familiares estão limitadas quando há uma criança com AA. Ações cotidianas podem ser vistas como ameaças à vida pelas crianças com essa patologia. A constante necessidade de planejamento para ir a festas ou comer fora de casa também pode ser gerador de ansiedade e estresse para o cuidador da criança com APLV. A família tenta manter a dieta segura para os seus filhos, mas as ingestões acidentais podem ocorrer, especialmente fora de casa. $\mathrm{O}$ medo de expor o filho ou filha ao possível componente alérgeno leva os cuidadores a evitar eventos sociais. Somado a isso, estão os dados de pesquisas que mostram que as mortes resultantes de reações alérgicas ocorrem fora do ambiente doméstico, comumente (GOMES et al., 2017).

É importante destacar que, ao passo que os cuidadores vão aumentando o conhecimento sobre a patologia, tendo melhores orientações nutricionais e ambientais, aprendendo a lidar e contornar as adversidades impostas pela APLV, vão também aumentando a percepção, e criando controle sobre a doença, gerando um maior empoderamento e segurança nas condutas com as crianças alérgicas (LINHARES, 2015).

\section{Processo Adaptativo da Família da Criança com APLV}

A promoção do acompanhamento familiar da criança com APLV é essencial para o equilíbrio e a segurança de todos os envolvidos, monitorando o consumo de alimentos proibidos, conduzindo uma alimentação apropriada, orientação e ensino da leitura de rótulos dos alimentos, reconhecimento e ações necessárias em caso de anafilaxia, ensino do uso correto da medicação, transmissão das informações necessárias aos espaços de convivência da criança (creche, casa de parentes, restaurantes, etc.), além de seguimento, a longo termo, da 
criança, para avaliação do prognóstico, assim como o desenvolvimento de outras alergias ou potencial tolerância (DIAS, 2016).

A dieta de exclusão deve ser acompanhada por um profissional de saúde especializado, pois caso haja desequilíbrio nutricional, outros problemas decorrentes da má alimentação podem acontecer. Deve-se preconizar uma alimentação balanceada, variada e completa, pois mesmo com a restrição à proteína do leite de vaca e seus derivados, a criança precisa receber os nutrientes necessários para um bom desenvolvimento (TEIXEIRA, 2010).

No que se refere às atividades fora do âmbito familiar, por exemplo, festas e viagens escolares e atividades de lazer, também aumentam o nível de preocupação, estresse e insegurança quanto à exposição acidental ao leite e seus derivados, fazendo com que esses momentos sejam evitados, frequentemente restringindo a sociabilização dessas crianças. Muitas crianças são privadas de ir em festas de aniversários ou a até mesmo à escola, tendo em vista que o leite é um dos alimentos mais presentes na dieta alimentar dos brasileiros e na sua culinária. E quando essas crianças já frequentam a escola, não partipam por vezes de comemorações que envolvem alimentos.(LINHARES, 2015).

Outro ponto relevante e que merece atenção do cuidador de crianças com APLV é a correta leitura dos rótulos dos produtos industrializados, que muitas vezes contém algum ingrediente ou traços da PLV, sendo, portanto, um potencial alérgeno (TEIXEIRA, 2010). De acordo com Solé (2012), 70\% da população brasileira lê os rótulos dos produtos que adquire, porém, apenas metade desse grupo compreende o significados das informações contidas nos produtos.

À equipe médica é indicada a averiguação e avaliação de cada caso, isoladamente, levando em consideração as necessidades especiais tanto da criança com APLV, quanto da família. É importante a prevenção de conflitos e desestruturação familiares, provenientes do desafio de lidar com crianças com a APLV. A família enfrenta desafios, obstáculos, decepções, incertezas e muitas surpresas. A APLV afeta não só a criança que é diagnosticada, mas também a família e os cuidadores, que devem ser encorajados a adotar uma rotina especial, de modo a minimizar o risco para a criança, ajustando seus papéis, para conseguir corresponder às necessidades da situação (DIAS, 2016).

Em um estudo citado por Dias (2016), as mães relatam que têm a qualidade de vida psicológica e física pior do que a relatada pelos pais, esse fato pode gerar conflitos familiares. Cerca de um em cada quatro pais relataram que a doença do seu filho teria causado uma 
pressão extra sobre o seu casamento e sua carreira profissional. O cuidado especial para com a criança também pode suscitar discordâncias entre o cuidador principal e a comunidade, a família ou o cônjuge. Pois é preciso um processo de adaptação onde toda a família contribua para livrar a casa de alérgenos além do planejamento de ações para a gestão dessa alergia, o que acaba frustrando a criança e toda a família.

É comum aos cuidadores abdicarem dos estudos, do emprego e das suas relações sociais para se dedicarem exclusivamente ao cuidado da família, mais especificamente, à criança com APLV. Tal fato contribui para o aumento da dependência financeira do companheiro, com consequente redução de sua autonomia e decréscimo de seu empoderamento. Há também os casos em que, além de ser o cuidador principal, a mãe é também a provedora principal da família, tendo que exercer sua atividade laboral e somar essa função às demais funções do dia a dia, triplicando seu trabalho (LINHARES, 2015).

Essa abdicação do trabalho pode influenciar na redução da renda mensal familiar e repercurtir diretamente na capacidade de sustento da família. Tais ações tem reações negativas tanto na esfera macroeconômica ou governamental, de maneira mais ampla, como na esfera microeconômica, representada no âmbito familiar, ou seja, na educação, alimentação, cuidados básicos e lazer da família, que muitas vezes estão associados à ocorrência de ansiedade e depressão nos cuidadores, ao se verem com dificuldades financeiras (SOUZA, 2016).

Outro ponto que exerce um impacto na vida dos cuidadores e que está diretamente relacionado ao ponto elencado anteriormente, é o da necessidade de abandonar o trabalho remunerado, associado ao alto custo das fórmulas especiais para a alimentação complementar de lactentes. No Brasil, há uma legislação vigente que busca alcançar três dimensões para garantir uma alimentação de qualidade para pessoas com necessidades específicas alimentares. O estado deve facilitar o desenvolvimento de condições para que todos possam alimentar-se adequadamente; deve promover formações, educação e informações pertinetes aos beneficiados pela lei; e por fim, prover uma alimentação adequada para as pessoas que estejam em situação de segurança alimentar ou má nutrição, no caso, dos pacientes diagnósticados com APLV (SOUZA, 2016).

Conhecer o contexto familiar, os medos, as preocupações, é um passo importante para o profissional de saúde. A falta de compreensão da comunidade em geral, a falta de vontade dos outros para contribuir com o cuidado e a adaptação da criança, a recepção das 
informações médicas inconsistentes e a ausência de informações nos rótulos dos produtos são as principais causas do sofrimento do cuidador da criança com APLV (DIAS, 2016). É importante destacar que a equipe de saúde deve estar munida de ferramentas que os auxiliem no enfrentamento do diagnóstico da APLV.

Muitos estudos têm evidenciado o efeito negativo da AA nas crianças, bem como na vida dos pais. Dias (2016), traz no seu estudo, uma pesquisa sobre o impacto da alergia alimentar nas atividades cotidianas das famílias com crianças com a APLV, revelando que metade das famílias relataram interrupçoes significativas nas atividades, ou seja, uma disfunção na rotina familiar. Mesmo assim, a atenção dada ao impacto dessas mudanças nos adultos ainda é pouco estudada. Para manter a rotina diária de cuidados com a alimentação da criança com APLV, percebe-se que o crescimento do tempo gasto com preparo dos itens e o esforço para promover um ambiente seguro, mostrando que o processo adaptativo da APLV tem um efeito notório na vida das famílias e dos cuidadores principais das crianças (GOMES et al., 2017).

\section{Considerações Finais}

O desenvolvimento da presente pesquisa, buscou conhecer e compreender os impactos vivenciados pelos cuidadores da criança diagnosticada com APLV. Inicialmente, observou-se que a caracterização da doença em questão é dificultada pela diversidade de sintomas apresentados. Muitas vezes, essa característica acaba confundindo a própria equipe médica, levando a tratamentos e intervenções medicamentosas que evoluem o quadro ou dificultam o correto diagnóstico, ocasionando o retardamento do tratamento adequado. A sintomatologia é vasta, variando desde uma dermatite atópica até uma enterocolite (inflamação do intestino). E infelizmente, ainda há profissionais de saúde que permanecem incrédulos ao quadro específico da APLV.

Sabe-se que a APLV é tratada através, principalmente, da exclusão total do leite de vaca e seus derivados da dieta da criança e, em alguns casos, da mãe quando a amamenta (quando lactante). Esses cuidados vão desde a adesão de uma nova dieta, livre da proteína de leite, até mesmo a exclusão de utensílios domésticos que mantiveram contato com o alérgeno (pratos, copos, esponjas, etc.). Outra recomendação, para casos específicos, é a dieta de 
exclusão também para a mãe que amamenta, pois através do contato com o leite materno, o bebê pode reagir, em caso de ingestão.

Ao deparar-se com um filho com APLV, o cuidador encontra inúmeras dificuldades e desafios que precisa transpor para proporcionar uma melhor qualidade de vida, apesar das limitações alimentares. Os principais desafios foram elencados na pesquisa. São eles: a dificuldade em diagnósticar a APLV, visto que os sintomas não são específicos e que não há exame próprio que identifique todos os tipos da doença; o processo de adaptação alimentar e ambiental torna-se minucioso e exaustivo, pois necessita de informação, educação e adaptação não só da criança, mas de todas as pessoas que convivem com ela (família, escola, festas); o alto custo da fórmula necessária para o tratamento da criança, pois nem sempre o governo disponibiliza o benefício imediatamente após o diagnóstico, levando o cuidador a uma luta judicial; e a abdicação ou ressignificação dos papeis sociais. Os cuidadores precisam acumular vários papéis dentro do cuidado com o filho com APLV e o restante da família, além de trabalhar fora e reeducar os demais membros da família e da escola.

Evidenciou-se, também, que o escopo teórico é escasso e direcionado principalmente para a área da saúde, mais precisamente, a área médica. Estudos multidisciplinares proporcionariam melhor abrangência das informações e atingiriam um público maior, promovendo maior disseminação do conhecimento. Auxiliando não somente os profissionais de psicologia ou áreas afins, mas também o público formado por mães, pais e/ou responsáveis pelos cuidados da crianca com APLV.

Esta pesquisa servirá como embasamento e fonte de pesquisa para que sejam elaboradas intervenções que busquem diminuir os impactos negativos vivenciados por cuidadores de crianças com APLV. Dessa forma, será possível a implantação e a promoção de serviços e ações direcionadas a essse público e que visem a prevenção de transtornos psicológicos, sofrimento e respostas emocionais negativas, após o diagnóstico, disponibilizadas pelas políticas públicas de saúde mental.

Investigou-se que as dificuldades enfrentadas pelos cuidadores estão diretamente relacionadas aos impactos emocionais negativos vivenciados pelos cuidadores. Viu-se que os principais problemas evidenciados pelos estudos selecionados são: alto custo da fórmula transcrita pelo médico especialista; dificuldades em manter o convívio social e familiar, em razão da mudança na rotina e na dieta da criança e, em alguns casos, da mãe; e ainda, o 
excesso de responsabilidades necessárias ao cuidador principal, que muitas vezes, precisa abdicar do trabalho, dos eventos sociais e até do lazer.

Dessa maneira, percebe-se que o objetivo primordial da pesquisa que era identificar aspectos emocionais envolvidos no cuidado da criança com alergia à proteína do leite de vaca, foi alcançado com êxito, através de pesquisa bibliográfica exploratória. Porém, o trabalho com essa temática ainda requer devotamento advindo principalmente da ciência psicológica, investigando não só os impactos vivenciados pelos cuidadores, mas também quais as alternativas de enfrentamento necessárias para evitar e, quando já presentes, trabalhar essas queixas em psicoterapia grupal ou individual.

A pesquisa contribuiu para ampliar o conhecimento sobre os impactos vivenciados no cuidado da criança diagnosticada com APLV, trazendo o olhar da psicologia e de outras áreas de estudo não só para as crianças, mas também para os seus cuidadores, que carregam muitas responsabilidades e sofrimentos relacionados ao excesso de funções acumuladas, ou seja, da sobrecarga que eles vivenciam diariamente.

\section{Referências}

AZEVEDO, A. L. S. et al. Doenças crônicas e qualidade de vida na atenção primária à saúde. Cad. Saúde Pública, Rio de Janeiro, v.29, n.9, p.1.774-1.782, set. 2013. Disponível em: $<$ https://www.researchgate.net/profile/Luciana_De_Avila_Quevedo/publication/257074718_ Chronic_diseases_and_quality_of_life_in_primary_health_care/links/551d328b0cf2a1533626 1179.pdf>. Acesso em 24 ago. 2017.

BRICKS, L. F.et al. Reações adversas aos alimentos na infância: intolerância e alergia alimentar - atualização. Pediatria, São Paulo, v. 16, n.4, p. 176-185, 1994. Disponível em: <http://www.luzimarteixeira.com.br/wp-content/uploads/2009/11/atualizacao-emintolerancia-alimentar.pdf>. Acesso em 07 jul. 2017.

CARDOSO, Ary Lopes. Manejo nutricional na alergia à proteína do leite de vaca. Pediatr.

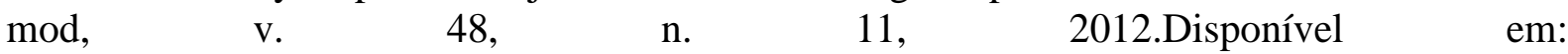
<http://www.moreirajr.com.br/revistas.asp?fase=r003\&id_materia=5225>. Acesso em 06set. 2017.

CASTRO, E. K.; PICCININI, C. A. Implicações da doença orgânica crônica na infância para as relações familiares: algumas questões teóricas. Psicologia: Reflexão e Crítica, v.15, n.3, p. 625-635 2002.Disponível em: <http://www.lume.ufrgs.br/bitstream/handle/10183/25669/000376038.pdf?sequence=1 >. Acesso em 30 ago. 2017. 
CEZA, Marília Rosso; FERREIRA, Cristina Targa. Tolerância oral no tratamento da APLV. Pediatr. $\bmod$, v. 51, n. 10, 2015.Disponível em: <http://www.moreirajr.com.br/revistas.asp?fase=r003\&id_materia=6169>. Acesso em 06set. 2017.

DIAS, Sara Gonçalves Sousa. A alergia alimentar e o impacto na criança e na familia. 2016. Dissertação de Mestrado. Disponível em: $<$ https://estudogeral.sib.uc.pt/bitstream/10316/36668/1/Tese\%20de\%20Mestrado\%20\%20Sara\%20Dias.pdf >. Acesso em: 14 set. 2017.

GIL, A. C. Como elaborar projetos de pesquisa. 4. ed. São Paulo: Atlas, 2008.

GOMES, Érika Campos et al.Alergia alimentar em crianças: implicações na vida familiar e no relacionamento fraterno. 2017.Disponível em:

<https://tede.pucsp.br/bitstream/handle/20012/2/\%C3\%89rika\%20Campos\%20Gomes.pdf > . Acesso em 27 out. 2017.

GUERRA, Thuany Coelho; BARRETO, Talita Kizzy Barbosa. Alergia alimentar ao leite de vaca em lactentes. In: Congresso Internacional de Atividade Física, Nutrição e Saúde. 2016.Disponível em: <https://eventos.set.edu.br/index.php/CIAFIS/article/view/3252/1224 >. Acesso em 11 ago. 2017.

LINHARES, Bruno Ferreira Rondon. Avaliação da qualidade de vida do responsável pela criança com Alergia à Proteína do Leite de Vaca (APLV). Dissertação de mestrado em Saúde da família. Universidade Estácio de Sá, 2015.Disponível em: <http://portal.estacio.br/media/922727/bruno-ferreira-rondon-linhares.pdf >. Acesso em 07 set. 2017.

MEDEIROS, Luana Búrigo. O fornecimento gratuito de leite com fórmula especial e o fenômeno da judicialização da saúde no Brasil. 2013.Disponível em: <http://dspace.unesc.net/bitstream/1/1911/1/Luana\%20B\%C3\%BArigo\%20Medeiros.pdf>. Acesso em 18 jul. 2017.

MINAYO, M. C. de S. O desafio do conhecimento. São Paulo: Hucitec, 1993.

PICCININI, Cesar Augusto et al. Expectativas e sentimentos da gestante em relação ao seu bebê. Psicologia: teoria e pesquisa. Brasília. Vol. 20, n. 3 (set./dez. 2004), p. 223-232, 2004.Disponível em: <http://www.scielo.br/pdf/ptp/v20n3/a03v20n3 >. Acesso em 31 ago. 2017.

PINHEIRO, A. et al. A prevenção primária da alergia alimentar é possível?-Caso clínico. Revista Portuguesa de Imunoalergologia, p. 457-464, 2009.Disponível em: $<$ http://repositorio.chlc.minsaude.pt/bitstream/10400.17/114/1/Rev\%20Port\%20Imunoalergologia\%202009_17_457.pdf >. Acesso em 28 set. 2017. 
PINTO, Ana Sofia Lopes. O Impacto das Alergias Alimentares no dia-a-dia. 2013. Tese de Doutorado. [sn].Disponível em: <http://bdigital.ufp.pt/bitstream/10284/4179/3/T_15717.pdf >. Acesso em 17 set. 2017.

RODRIGUES, Angélica; RODRIGUES, Míriam Carmo. Vida e sabor sem leite. 2011.Disponível em: <http://repositorio.ufop.br/bitstream/123456789/4567/6/LIVRO_VidaSaborLeite.pdf>. Acesso em 03 out. 2017.

SEKITA, Shigeru Ricardo. A alergia a proteína do leite de vaca e seu impacto no ganho de peso de um lactente: relato de caso. Revista Eletrônica Parlatorium Ano IV-Volume 9 (2) Julho-Dezembro de 2015, p. 56, 2015.Disponível em: $<$ http://faminasbh.edu.br/upload/Parlatorium\%2092016_2.pdf\#page=56 >. Acesso em 07 set. 2017.

SOLÉ, Dirceuet al.. Consenso brasileiro sobre alergia alimentar: 2007. Rev. Bras. Alerg. Imunopatol., $\quad$ v. $31, \quad$ n. $2, \quad 2007 . \quad$ Disponível em: <http://nutricaoemfoco.com.br/NetManager/documentos/consenso_brasileiro_sobre_alergia_a limentar.pdf>. Acesso em 03 set. 2017.

SOLÉ, Dirceu et al. Guia prático de diagnóstico e tratamento da Alergia às Proteínas do Leite de Vaca mediada pela imunoglobulina E. Rev. bras. alerg. imunopatol.-Vol, v. 35, n. 6, 2012.Disponível

em: $<$ https://www.researchgate.net/profile/Nelson_Rosario/publication/235970750_Guia_pratico_ de_diagnostico_e_tratamento_da_Alergia_as_Proteinas_do_Leite_de_Vaca_mediada_pela_i munoglobulina_E/links/004635150449f2458a000000/Guia-pratico-de-diagnostico-etratamento-da-Alergia-as-Proteinas-do-Leite-de-Vaca-mediada-pela-imunoglobulina-E.pdf >. Acesso em 04 set. 2017.

SOUZA, Juliana Carneiro de et al. Acesso à alimentação especial no Brasil: política pública direitos humanos. 2016.Disponível em: <http://repositorio.bc.ufg.br/tede/bitstream/tede/7932/5/Disserta\%C3\%A7\%C3\%A3o\%20\%20Juliana\%20Carneiro\%20de\%20Souza\%20-\%202016.pdf >. Acesso em 07 set. 2017.

TEIXEIRA, Liliana Marlene Oliveira. Alergia às proteínas do leite de vaca: Monografia: Cows Milk Protein Allergy. 2010.Disponível em: <https://repositorioaberto.up.pt/bitstream/10216/54529/4/137223_1006TCD06.pdf >. Acesso em 03 set. 2017.

VERÍSSIMO, Daniela Maria Maia. Um estudo sobre a ambivalência materna em mães de crianças com alergia à proteína do leite de vaca. 2009.Disponível em: $<$ https://repositorio.unesp.br/bitstream/handle/11449/97559/verissimo_dmm_me_assis.pdf?se quence $=1 \&$ isAllowed=y $>$. Acesso em 24 ago. 2017.

VISINTIN, Carlos Del Negro et al. Maternidade e sofrimento social estudo de mommy blogs. 2016.Disponível em: <http://tede.bibliotecadigital.puccampinas.edu.br:8080/jspui/bitstream/tede/895/2/MATERNIDADE\%20E\%20SOFRIMENT 
O\%20SOCIAL\%20ESTUDO\%20DE\%20MOMMY\%20BLOGS.pdf >. Acesso em 13set. 2017.

YONAMINE, Glauce Hiromi et al. Percepção dos familiares de pacientes com alergia ao leite de vaca em relação ao tratamento. Journal of Human Growth and Development, v. 23, n. 1, p. 58-64, 2013.Disponível em: <http://pepsic.bvsalud.org/scielo.php?script=sci_arttext\&pid=S0104-12822013000100009 >. Acesso em 29 ago. 2017.

\section{Como citar este artigo (Formato ABNT):}

ABAGARO, Raíza M. de A.; MARANHÃO, Thércia L. G.; ROCHA, Nicole G.N.; SOBRAL, Stevens E. C.; SOBRAL, Maria L. C. Aspectos Emocionais Vivenciados pelos Pais e/ou Cuidadores de Crianças com Alergia à Proteína do Leite de Vaca. Id on Line Revista Multidisciplinar e de Psicologia, 2018, vol.12, n.39, p. 736-756. ISSN: 1981-1179.

Recebido: 19.01 .2018

Aceito: 26.01.2018 